will be dry and parched. Extensive schemes of irrigation and water conservation have been carried out or are nearing completion, and delegates had the opportunity of appreciating the magnitude of these schemes by visits to the Snowy Mountains and to dams under construction, such as that at Warragamba.

To-day there are stud farms where the merino stock is maintained, and the delegates were able to visit such studs near Deniliquin and those in the Macquarie Valley region in Tasmania, where a very pure strain of fine-woolled merinos is maintained. Research on genetics and growth of sheep by the Commonwealth Scientific and Industrial Research Organization has been most active. The occurrence of 'steely wool' and malnutrition of the sheep was traced to cobalt deficiency. The wide need for phosphate fertilization of the soil was demonstrated, and to-day problems such as 'staggers' due to Phalaris tuberosa are being investigated.

The people of Australia in general and the graziers in particular have come to appreciate the invaluable work of the Commonwealth Scientific and Industrial Research Organization, and the importance of the Conference to Australia was indicated by the presence of the Prime Minister and several colleagues at the inaugural dinner, and by the reception of all delegates by the Governor-General and Lady Slim at Canberra. A. B. D. CAsste

F. O. How TT

\title{
SOIL MECHANICS, GEOLOGY AND CIVIL ENGINEERING
}

$\mathrm{D}$ URING the recent meeting at Bristol of the British Association, a most informative joint meeting between Section C (Geology) and Section G (Engineering) took the form of a symposium to discuss the interdependence of geology, civil engineering and the new science of soil mechanics. Mr. F. H. Edmunds, of the Geological Survey of Great Britain, introduced the discussion. He pointed out that the civil engineer, in order to make an appreciation of the likely reactions of the rocks to his activities, requires as full geological information as possible concerning a new site, particularly in regard to the physical characteristics of rocks as determined from small samples (their hardness, cohesion, porosity of the rock) ; the arrangement of rock masses and strata at an engineering site (whether they lie horizontally or are inclined or buckled or folded, etc.) ; and the potentialities of water storage in, and movement through, the rocks. Detailed geological information is more necessary to-day than in former years for two main reasons: through advances in technique and machinery, many civil engineering works of to-day are immensely larger and more complex than those of past days; and whereas the old engineers usually had the choice of site, present-day works often have to be constructed at sites imposed on the engineer. These may be on alluvial tracts, in coastal areas, or in other difficult situations where the ground is occupied by thick beds of unconsolidated material, in many instances saturated with water.

Up to thirty years ago, geological science had more or less ignored petrological studies of soft sediments. The physical characteristics of soft rocks and, in the case of clays, differences of behaviour relative to the variable factor of the amount of adsorbed water in them, had received scant notice; but these points are of vital importance to engineers. In the circum. stances, engineers and physicists set out themselves to get information of the kind required. From their work has evolved the science of 'soil mechanics'.

The word 'soil' in this connexion connotes soft unconsolidated material irrespective of its thickness or of its depth below ground surface; it has but little connexion with the top several inches of the earth's crust associated with agriculture. Generally speaking, what the engineer calls 'soils' are the 'soft rocks' of geological terminology, for example, sand and clay. Their essential feature, however, is lack of consolidation.
Much of soil mechanics investigations is a matter of physics undertaken in the laboratory, but laboratory tests by themselves are incomplete. To obtain the fullest information from them the small samples used need to be related to the stratigraphy of the beds from which they are taken.

Mr. P. L. Capper, of University College, London, described the fundamentals of soil mechanics. Soilused in the engineering sense-necessarily forms, in its natural condition, the foundation for all works of construction, except where these can be founded directly upon solid rock. It is also used extensively as a constructional material, for example, in embankments, dams and earth roads. In designing any members of an engineering structure, four points have to be considered : the load or external forces applied to the member ; the internal forces and stresses set up in the member ; the deformations produced; and the way in which failure will take place if the member is overloaded. The same applies to soil ; but compared with other materials of construction, soil presents greater difficulties on account of its lack of uniformity and its susceptibility to changes in its properties arising from variation in the water content. Soil mechanics comprises three main divisions : mechanics of soils, that is, the loss of equilibrium induced by engineering work, stress distribution and movement of water in soil; site investigation and the testing of soil for the determination of the relevant properties; the application of the findings under the first two headings for civil engineering design and construction.

The first division of soil mechanics includes the study of the conditions of stability of masses of soil, the determination of the internal stresses set up in soil under the action of external and gravitational forces and study of the laws governing the movement of water in soil. As with other engineering materials, the solution of stability and stress-distribution problems in soil involves an application of statics combined with assumptions as to deformation characteristics such as elasticity or plasticity.

In deciding upon the depth to which an investigation should be carried out, the chief point is to estimate the depth of soil which will be appreciably affected by the applied loads, and this depends upon the extent of the loaded area. The concept of the bulb of pressure illustrates this principle. The most important soil properties from the engineer's point of 
view are compressibility, shear strength and permeability. The compressibility of soil, in the broadest sense of the word, may be defined as the relation between compressive deformation and the pressure producing it. The deformation may result from one or more of the following factors : it may be elastic, recoverable when the pressure is removed; plastic, due to plastic flow of material ; or may result from consolidation or closer packing of the particles resulting from the expulsion of water. In clay soils the settlement due to consolidation may be of considerable magnitude but is a very gradual process.

The shear strength of soil is assumed to be made up of two components: intergranular friction and cohesion. Generally speaking, sands and gravels derive their strength almost entirely from friction, whereas in clay soils cohesion predominates.

Reviewing the rapid development of soil mechanics, it is seen that a vast amount of knowledge, theoretical and practical, has been accumulated in a comparatively short period of time. If this knowledge is to be used to the best advantage in civil engineering, careful study must be made of 'case history', that is, observation of engineering works during construction and while in ordinary use. Also, every opportunity should be taken of investigating thoroughly any failures which are attributable to the soil. Soil mechanics is not, and never can be, an exact science, and its successful application always calls for experience and common sense.

Two papers on direct applications of soil mechanics and geology to civil engineering followed, delivered respectively by Mr. A. H. Toms, of the Civil Engineer's Department, British Railways, Southern Region, and by Mr. D. F. C. Henry, of the University of Leeds.

It was not until about 1937-38 that the scientific study of the physical and engineering properties of soils was taken up by one or two selected civil engineers of British Railways with the view of obtaining better understanding of the many landslips and other soils problems with which British Railways are faced. In the case of landslips, calculation, taking into account the mechanics of the slipping masses, the water pressures and the resistances offered by the soil, now often enables a far more rational approach to be made to the remedial measures than was possible before the advent of the science of soil mechanics.

The biggest single landslip problem affecting British Railways is that of the coastal landslips of the Folkestone Warren, Kent. There the railway runs for two miles continuously across a great expanse of slipped chalk and Gault clay resulting not from a lubricated surface between the Chalk and the Gault as formerly assumed, but from shear failure of the Gault in its basement bed on top of the Lower Greensand. The Middle and Lower Chalk form cliffs rising to $+550 \mathrm{ft}$. O.D. behind the wide stretch of slipped ground, while the Gault underlies the whole of the affected area. In 1938, research was commenced into the nature of the slips, which were then once again beginning to threaten the stability of the railway. Test boreholes were sunk over a wide area down to depths of $300 \mathrm{ft}$. and many soil samples were extracted for visual inspection and special testing. In this work fossil identification and the recognition of stratigraphical horizons by the geologist proved of the utmost value in supplementing the information obtained from soil mechanies tests.

As a resuli of the research at the Warren, an extensive programme of stabilization works has been put in hand consisting of : (1) new sea walls farther out to sea, with filling behind protected by concrete slabs in order to provide toe weight on the foreshore; (2) drainage of water out of the slips by means of a new tunnel heading; (3) overhaul of all existing drainage headings and groynes; and (4) repair to old groynes and provision of new ones.

It has been found by experience that in many cases of substation buildings, signal boxes and bridges the design of the foundations is determined, not by the shear strength of the ground but by its consolidation settlement under the load. One of the most difficult problems which arises in connexion with the estimation of the probable settlement of structures is that in which a group of piles may be required to transmit the foundation load to a layer of soft compressible soil, the thickness of which is too great to permit the piles to penetrate to firmer material below. Novertheless, it has proved possible to arrive at reasoned estimates of probable settlements in such cases, a typical one being that of proposed pile groups for new side spans to the Kingsferry Bridge over the Swale, where there is a great depth of soft alluvium overlying London Clay of varying strength.

Typical of the application of soil mechanics to the solution of tunnel stability problems is the case of Bo-peep Tunnel, Hastings. This double-lined tunnel passes through the Wadhurst Clay. A few years ago it was noticed that the tracks near the western end of the tunnel were rising, the side walls were closing in and houses over the top started to subside. Steps were taken at once to put temporary supports in the tunnel to arrest the movement. Very careful investigations revealed that the movements were due to shear failure of the ground in the side-wall footings. This had been brought about by very slow progressive softening of the ground under the tracks on account of the combined action of percolating water and the dynamic effects of rail traffic.

Following this instance, extensive soil mechanics investigations were made in both Hastings and Ore tunnels, and major strengthening works were put in hand.

Mr. Henry described some soil mechanics aspects of the design of pad, strip and raft foundations located on the surface of the ground or at a relatively shallow depth. Recent experimental investigations include those of Golder, who in 1941 carried out tests on axially loaded model footings ranging in size from 6 in. $\times 6$ in. to 30 in. $\times 6$ in. on the surface of clean dry river sand contained in a, $3 \mathrm{ft} .6$ in. $\times 3 \mathrm{ft} .6 \mathrm{in} . \times$ 14 in. deep box. Tests were also carried out on foot. ings ranging from 3 in. $\times 3$ in. to 18 in. $\times 3$ in. on remoulded London Clay in $2 \mathrm{ft} .6 \mathrm{in} . \times 1 \mathrm{ft} .8 \mathrm{in} . \times$ 8 in. deep box. Meyerhoff made some tests on footings on sand contained in a box with a glass front; the inside of the glass was smoked so that the movements of the grains under load were automatically scribed on the glass. In another series of tests, vertical and eccentric loads were applied on footings of various lengths and 1 in. wide on the surface of, and at shallow depths in, loose and medium Ham River sand and remoulded London Clay.

More experimental evidence based on larger footings tested on the surface of, and at a depth in, sand and clay and loaded with axial and eccentric loads is desirable. In planning tests, the elimination of restraint due to confinement of the soil is necessary, and the results must be carefully analysed in the light of what is known concerning the behaviour of soils under stress and the modes of failures of footings. 
Mr. Henry concluded that the present position of soil mechanics aspects of foundation design is reasonably satisfactory. Where soil conditions are straight. forward or the structure is not large-for example, a domestic house or a small retaining wall-then simple investigations of the site and tests coupled with elementary soil mechanics theories are sufficient for practical work. On the other hand, considerable practical experience and theoretical knowledge is required where soil conditions beneath projected important structures are complex, and the interpretations of investigations and recommendations are best placed in the hands of specialists.

The engineer will never be able to escape the fact that soil is the most variable material with which he has to deal, and even where a mass of soil is apparently of uniform type, its physical properties may vary considerably. Apart from general changes in physical properties which may occur across a site, there are innumerable local variations which would entail much work to determine and take into account directly. In suitable cases such local variations can be catered for in the design of important structures by means of a coefficient of variation, in the nature of a factor of safety, based on the magnitude and frequency of properties revealed by soil mechanics tests.

The symposium was attended by a large audience and admirably exemplified the value of joint meetings between sections, a feature that becomes yearly more desirable with the rapidly increasing degree of inter. digitation of the different sciences. Interest in the meeting was accentuated by the kindness of Engineering in providing pre-prints of the several papers, and of the Soil Mechanics Department of the University of Bristol in furnishing apparatus for purposes of demonstration.

F. H. EDMUNDS

\section{LIGHTING AND VISION}

$\mathrm{T}$ HE discussion on lighting and vision in Section I (Physiology) of the British Association during the recent Bristol meeting was opened by four speakers whose papers dealt with some important aspects of the subject.

In the first paper, H. C. Weston, director of the Medical Research Council's Group for Research in Occupational Optics, gave a brief account of some of the studies of human responses to varieties of lighting that have been made in recent decades with the object of providing scientific knowledge as a basis for planning lighting, particularly for building interiors. A number of these studies which have influenced present concepts of good lighting practice have been made in Great Britain, under the ægis of the Medical Research Council and the Department for Scientific and Industrial Research. They were primarily prompted by concern for the welfare of people at work and for their occupational efficiency.

Thus, in the early twenties, Elton, Weston and Wyatt each studied the effects of lighting upon the performance of weavers, which was shown to vary with the amount of illumination available up to about $30 \mathrm{~lm} . / \mathrm{ft}^{2}{ }^{2}$. Weston and Taylor varied the illumination provided for printing compositors, and found that the rate and accuracy of working was proportional to the logarithm of the illumination value up to a level of $25 \mathrm{Im} . / \mathrm{ft}^{2}{ }^{2}$. They also showed that if the lamps used were so placed as to be glaring, work was impeded and the effectiveness of a given value of illumination on the work was reduced.

McDermott determined the desirable illumination for the work of typists, and Adams studied the response of persons doing visually unexacting work under different conditions of lighting. By such fieldstudies in occupations, chosen because their visual demands seem typical of whole classes of occupations, it was hoped to determine a scale of values of illumination adequate on physiological and psychological grounds for diverse purposes. This is a lengthy and difficult procedure, and a more fundamental approach was suggested by Beuttell in 1933. Pointing out that the visibility of all objects depends on certain of their characteristics, chiefly their size, contrast and luminance, he proposed that the relations between these variables be ascertained experimentally, so that levels of illumination could be computed for any visual task the critical components of which could be measured.

Using a suitable series of standardized tasks, Weston determined these basic relations, and his data are widely used internationally in prescribing illumination for good visual performance. $\mathrm{He}$ has also shown the effect of age upon the performance of these visual tasks and how it varies with different levels of illumination.

A much studied aspect of lighting is glare. Current rules of practice for the avoidance of this evil are due largely to the experimental studies of Stiles and, more recently, of Hopkinson and others at the Building Research Station. Responses to a variety of other features of lighting have been and still are being studied scientifically. Although recent advances in knowledge of lighting requirements, as well as in lighting techniques, are being applied fairly extensively, there is no doubt that the present lighting of many homes, schools, hospitals, offices, factories and other places is poor ; not very rarely it is almost incredibly bad.

The investigations described by W. R. Stevens, head of the Illumination Group, General Electric Com. pany's Research Laboratories, Wembley, were made by Foxell and Stevens to explore the dependence of the capacity for seeing detail upon the luminance of the object looked at and the luminance of fields of different size surrounding the object. Lythgoe (1932) showed that, except at low values of test-object luminance, the visual acuity attainable is better when the surrounding field of view has a luminance not very much below that of the test-object than when this field has zero or almost zero luminance.

On the basis of this finding, it has been widely held that lighting for good seeing should brighten the whole apparent environment almost as much as it brightens the given object of attention. However, Lythgoe did not study the effect upon acuity of luminous surrounds of test-objects when the surrounds do not entirely fill the visual feld. Foxell and Stevens have done this, and have also measured acuity at higher values of luminance than Lythgoe used. 'They made, altogether, about 100,000 observations, using a Landolt broken ring as test-object The ring was presented in contrast with a central field subtending an angle of $0.5^{\circ}$ at the eyes of the 